\title{
Knowledge and Attitude about Infertility among Infertile Males at Main Assiut University Hospital.
}

\author{
Fares A. Mahdi, Neama M. Almagraby, Sabra M. Ahmed \& Nagla S. Abd ELatty. \\ Clinical Nurse Specialist in Al-Kuwait University Hospital,Yemen. \\ Assistant Professor of Community Health Nursing, Faculty of Nursing, Assiut University, Egypt. \\ Assistant Professor of Public Health, Faculty of Medicine, Assiut University, Egypt. \\ Lecturer of Community Health Nursing, Faculty of Nursing, Assiut University, Egypt.
}

\begin{abstract}
Background: Male infertility is a common and severe health problem. Infertility not only affects one's ability to have children, but also has emotional, psychological, family, and societal effects. Aim of the study: to assess knowledge and attitude about infertility among infertile males.Methods: Cross-sectional research design was used in the study. (Setting) The present study was conducted at outpatient's clinic of dermatology and andrology department at Main Assiut University Hospital. The sample of this study consisted of 200 infertile male who had come to outpatient's clinic of dermatology and andrology department Tools was utilized for data collection were infertile male knowledge and attitude questionnaire sheet. The results show that generally poor level of knowledge $(62 \%)$ and a negative attitude $(65.5 \%)$ toward male infertility. There were statistically significant differences between personal characteristics of infertile male and their knowledge and attitudes regarding male infertility. Conclusion: The sample study of the infertile male had poor knowledge about male infertility and had a negative attitude toward male infertility. Recommendations: Health education for males about infertility. Increase public awareness about infertility through mass media.
\end{abstract}

Keywords: Male Infertility, Knowledge, Attitude\& Assiut University Hospital.

\section{Introduction}

Infertility is a global phenomenon that affects between 60 million and 168 million people worldwide. Infertility is defined as the inability to achieve a successful pregnancy after 12 months of unprotected intercourse or therapeutic donor insemination (Practice Committee of the American Society for Reproductive Medicine, 2013).

Male Infertility was not just a medical condition to be treated with fertility drugs, surgery or assisted reproductive technology, but it may lead to depression, suicidal tendencies, and other pathologic psychological conditions was often a crisis that profoundly affected nearly all aspects of one's personality and life (Katwsa, 2013).

Global male infertility prevalence rates are difficult to determine, due to the presence of both male and female factor (Gerhard et al,2014). Worldwide infertility is generally reported as occurring in $8-12 \%$ of all couple. An estimated $15 \%$ of the world population including 6 million couples in the USA are affected by infertility. A male factor is responsible in about $50 \%$ of infertility cases; it is the sole reason in about $20 \%$ of the cases and is a contributory factor in 30-40\% of the cases

(Orisakwe, 2014).

According to a study conducted by the Egyptian Fertility Care Society and sponsored by the World Health Organization (WHO), infertility in Egypt affects 12 percent of Egyptian couples (Sallam, 2013).

Male infertility is caused by various factors, such as disorders of the endocrine system, disturbances in ejaculation, bacterial or viral infection, immunologic factors, varicoceles, undescended testis and anabolic steroid use. However, a clear etiology cannot be determined for many cases of male infertility. Excluding patients who have previously had a vasectomy, nearly $10 \%$ to $15 \%$ of men have azoospermia, a condition in which semen is produced but does not contain sperm (Lee et al., 2012)

There are two types of infertility: Primary infertility: inability to get have children after one year of continuous marital relations, in the absence of contraceptive use. Secondary infertility is when a man do not conceive after one year of trying, despite having conceived children in the past without any problems(Jimoh, 2013).

The diagnosis of male infertility must focus on a number of prevalent disorders (Semen test, Ultrasonography and Testicular biopsy (Lee et al., 2012).

Medical treatment for male infertility generally falls under two categories:-

Specific therapy and empiric therapy and the surgical management of male infertility provides many options to the couple with male factor infertility. 
Problems amenable to surgery include varicoceles, obstruction, or sperm retrieval for In vitro fertilization (IVF) with intracytoplasmic sperm extraction (Jungwirth et al., 2012).

Nurse are often the first health care provider to encounter couples with treatment period, Fertility clinic nurse often need to advise, counsel and support couples in their coping with infertility- and treatmentrelated stress. It is, therefore, important to gain insight into the mechanisms which influence the patients' coping response (Schmidt, et al, 2014).

\section{Significance of the study}

Reproductive health in Egypt focused mainly on women health and ignoring the role of men, in spite of the important role that men are playing in reproduction and fertility, which impact his family and environment. (Leonardo, et al, 2012)

In the last 50 years, a significant decrease in human fertility has been observed. It has also been stated that $15 \%$ of couples have fertility problems. Among infertile couples, man is responsible for $50 \%$ from cases of infertility. The studies indicate that $6 \%$ of men aged 15-44 years are infertile or their fertility is significantly compromised (Smith et al., 2009).

Reports in recent years have shown that incidence of male infertility has increased as a result of various factors such as environmental pollution, stress, and lifestyle (Mishra, et al, 2012).

\section{Aim of the study}

The Aim of Study:

To assess knowledge and attitude about infertility among infertile males at Main Assiut University Hospital.

\section{Research question}

- What is the level of knowledge and attitude about infertility among infertile males attending Assiut University Hospital?

- Is there a relationship between knowledge and attitude about infertility among infertile males and the socio - demographic characteristic of infertile males?

\section{Subjects \& methods}

\section{Research design}

Cross-sectional study designs were used in conducting this study.

Technical design

\section{Setting of the study}

The present study was conducted in infertile male's dermatology and andrology outpatient's clinics at Main Assiut University Hospital.

\section{Sample}

A convenient sample of infertile males who attended the dermatology and andrology outpatients' clinic at Main Assiut University Hospital. The total number of the study sample was 200 adults infertile male suffering from infertility was chosen for conducting the study.

They were selected from the above mentioned setting, according to the following criteria; all males suffering from infertility both types primary and secondary.

\section{Tools of data collection}

Tool (1): structured interview questionnaire sheet: After reviewing the literature and researchs which were relevant to the present study, data were collected through using an interview questionnaire sheet to assess infertile male's knowledge regarding male infertility. It included the following parts:-

Part (1): This part was concerned with personal characteristics of infertile males it included: - age, residence, occupation, education, duration of the marriage, number of marriages, number of his children.

Part (2): included questions related to knowledge about infertility among infertile male, such as definition of male infertility, risk factor about male infertility, causes of male infertility, signs and symptoms of male infertility, diagnosis, and treatment of male infertility.

- The scoring system, for each item, a correct response was scored one grade and the incorrect scored zero.The score of items was summed-up and then converted into percent score. Knowledge was considered poor if less than $50 \%$, fair if the percent score was $(50 \%-65 \%)$ and good more than $65 \%$ (Elshafy et al., 2013).

Tool (2): Attitude rating scale:- Likert scale adapted from (Elshafy et al., 2013) was used to assess infertile male attitude regarding infertility.

- $\quad$ It consisted of 23 statement about male infertility. The responses were on a three-point Likert scale ranging from agree, uncertain and disagree.

- The scoring system the responses (agree, uncertain and disagree). were respectively scored 2, 1 and zero. The scoring was reversed for the negative statement. The scores of items were summed up by the number of items, giving a mean score of part these scores were converted into a percent score. The attitude was considered positive if the present score was $60 \%$ or more and negative if less than $60 \%$ (Elshafy et al., 2013).

\section{Operational design}

Data collection procedure was carried out in two phases 


\section{Phase 1: preparatory phase}

It includes reviewing of current literature and international related literature in the various aspects of the problems using textbooks, articles, and Journals in order to develop the study tools for data collection

\section{The pilot study}

A pilot study was conducted on first twenty infertile male of the sample. The purpose of the pilot study was to detect any particular problem in the statements clarity, to estimate the time required to fill the questionnaire and applicability of the tool. No modification was done in the assessment sheet, so the infertile male selected for the pilot study were included in the main study.

\section{Phase 2: Field work}

Data was collected from the dermatology and andrology outpatient clinic of Main Assiut University Hospital during the period (from beginning February /2015 to begin August /2015). The researchers attended in the study setting three days per week, a number of patients range from 1 to 3 every day, all tools were filled through interviewing each patients individually. The purpose of the study was explained to every person prior to answering the question. The average time taken for completing each interview was around 30 minutes or more depending on the person response to a question.

\section{Administrative design}

An official approval letter was obtained from the Dean of Faculty of Nursing, Assiut University to the director of dermatology and anderology outpatients clinics at Main Assuit University Hospital. This letter was included a brief explanation for purpose of the study.

\section{Ethical considerations}

The research proposal was be approved from Ethical Review committee in the Faculty of Nursing. There was no risk for study subjects during application of research also the study followed common ethical principles in clinical research, oral consent was obtained from participant or guidance that were willing to participate in the study after explaining the nature and purpose of the study, study subjects had the right to refuse participation and or withdraw from the study without any rational at any time and study subject privacy will be considered during collection of data.

\section{Statistical analysis}

The collected data were reviewed, prepared for computer entry, coded categorized, analyzed and tabulated. Descriptive statistics as mean, standard deviation, number, and percentage. Were done using SPSS version 21. Statistical significance was considered at
$\mathrm{P}$ value were less than $0.05(\mathrm{p}<0.05)$. The t-test is used to determine significance for the numeric variable. The chi-square test is used to determine significance for the non-parametric variable, also correlation by Pearson Correlation. 


\section{Results}

Table (1): Distribution of infertile males attending Main Assiut University Hospital according to their Personal characteristics, 2015.

\begin{tabular}{|c|c|c|c|}
\hline Items & Frequency No. (200) & Percentage & $\%$ \\
\hline \multicolumn{4}{|l|}{ Age by years } \\
\hline$<30$ & 66 & 33.0 & \\
\hline $30-<45$ & 108 & 54.0 & \\
\hline$>45$ & 26 & 13.0 & \\
\hline Mean \pm SD & \multicolumn{3}{|c|}{$34.9 \pm 8.9$} \\
\hline \multicolumn{4}{|l|}{ Level of education } \\
\hline Illiterate & 38 & 19.0 & \\
\hline Read \& write & 27 & 13.5 & \\
\hline Basic education & 32 & 16.0 & \\
\hline Secondary & 78 & 39.0 & \\
\hline University \&High & 25 & 12.5 & \\
\hline \multicolumn{4}{|l|}{ Occupation } \\
\hline Government employee & 70 & 35.0 & \\
\hline Private work & 40 & 20.0 & \\
\hline Free works & 90 & 45.0 & \\
\hline \multicolumn{4}{|l|}{ Residence } \\
\hline Urban & 35 & 17.5 & \\
\hline Rural & 165 & 82.5 & \\
\hline \multicolumn{4}{|l|}{ Duration of marriage } \\
\hline$<3$ & 94 & 47.0 & \\
\hline $3-<6$ & 42 & 21.0 & \\
\hline $6-<9$ & 34 & 17.0 & \\
\hline$>9$ & 30 & 15.0 & \\
\hline Mean \pm SD & \multicolumn{3}{|c|}{$4.9 \pm 2.2$} \\
\hline \multicolumn{4}{|l|}{ Number of marriage } \\
\hline One & 187 & 93.5 & \\
\hline Two & 13 & 6.5 & \\
\hline \multicolumn{4}{|l|}{ Number of children } \\
\hline None & 169 & 84.5 & \\
\hline One & 31 & 15.5 & \\
\hline
\end{tabular}

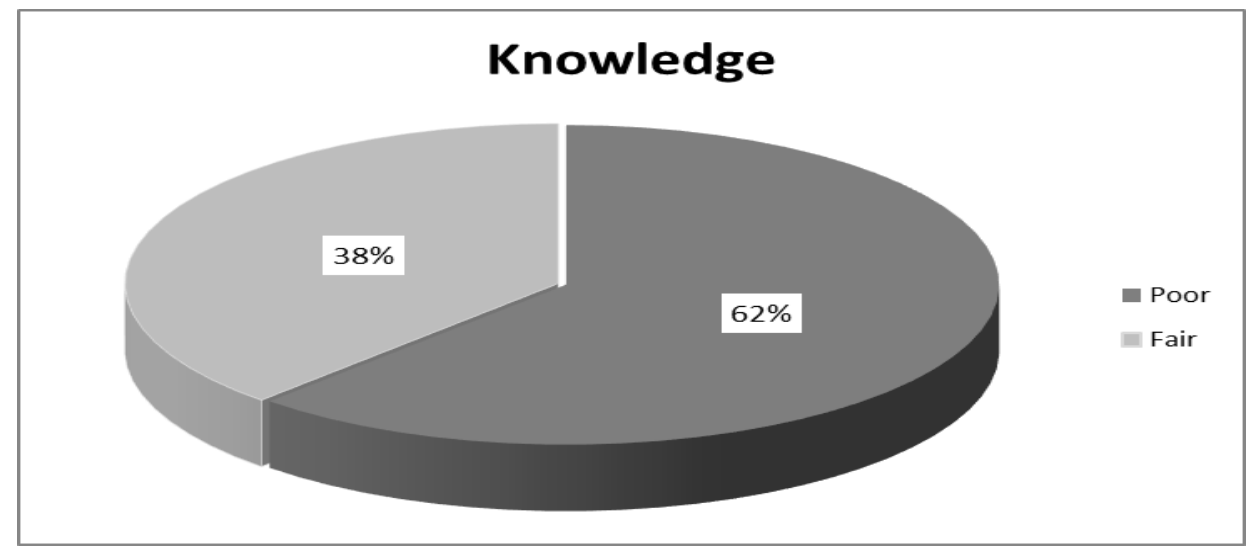

Figure (1): Total score of knowledge of infertile males attending Main Assiut University Hospital about male's infertility, 2015. 
Table (2): Total score of attitude of infertile males attending Main Assiut University Hospital about male's infertility, 2015.

\begin{tabular}{|l|c|c|}
\hline \multicolumn{1}{|c|}{ Attitude } & No. & \% \\
\hline Negative & 131 & 65.5 \\
\hline Positive & 69 & 34.5 \\
\hline
\end{tabular}

Table (3): Distribution of infertile males who attending Main Assiut University Hospital, according to their knowledge about male infertility, 2015.

\begin{tabular}{|l|c|c|}
\hline \multirow{2}{*}{ Items } & \multicolumn{2}{c|}{ Infertile male } \\
\cline { 2 - 3 } & \multicolumn{2}{|c|}{ No. } \\
\hline What is the source of your information about infertility? \\
\hline Physicians & 120 & 60 \\
\hline Parents & 22 & 11 \\
\hline Friends & 18 & 9 \\
\hline Newspaper & 4 & 2 \\
\hline Television & 10 & 5 \\
\hline Internet & 25 & 12.5 \\
\hline Radio & 1 & 0.5 \\
\hline
\end{tabular}

* More than one answers were selected

Table (4): Relation between personal characteristic of infertile males Attending Main Assiut University Hospital and their total score of knowledge about male infertility, 2015.

\begin{tabular}{|c|c|c|c|c|c|c|}
\hline \multirow{2}{*}{ Characteristics } & \multicolumn{2}{|c|}{ Poor $(n=124)$} & \multicolumn{2}{|c|}{ Fair $(n=76)$} & \multirow[t]{2}{*}{$\overline{X^{2}}$} & \multirow[t]{2}{*}{ P. value } \\
\hline & No. & $\%$ & No. & $\%$ & & \\
\hline \multicolumn{7}{|l|}{ Age in years } \\
\hline$<30$ & 25 & 20.2 & 41 & 53.9 & \multirow{3}{*}{32.1} & \multirow{3}{*}{$0.000 *$} \\
\hline $30-<45$ & 86 & 69.4 & 22 & 28.9 & & \\
\hline$\geq 45$ & 13 & 10.5 & 13 & 17.1 & & \\
\hline \multicolumn{7}{|l|}{ Level of education } \\
\hline Illiterate & 34 & 27.4 & 4 & 5.3 & \multirow{5}{*}{55.9} & \multirow{5}{*}{$0.000 *$} \\
\hline Read \& write & 15 & 12 & 12 & 15.8 & & \\
\hline Basic education & 17 & 13.7 & 15 & 19.7 & & \\
\hline Secondary & 44 & 35.6 & 34 & 44.7 & & \\
\hline University and high & 14 & 11.3 & 11 & 14.5 & & \\
\hline \multicolumn{7}{|l|}{ Occupation } \\
\hline Government employee & 36 & 29.0 & 30 & 39.5 & \multirow{3}{*}{19.1} & \multirow{3}{*}{$0.000 *$} \\
\hline Private work employee & 23 & 18.5 & 20 & 26.3 & & \\
\hline Free work & 65 & 52.5 & 26 & 34.2 & & \\
\hline \multicolumn{7}{|l|}{ Duration of marriage } \\
\hline$<3$ & 57 & 46.0 & 37 & 48.7 & \multirow{4}{*}{11.3} & \multirow{4}{*}{$0.010^{*}$} \\
\hline $3-<6$ & 24 & 19.4 & 18 & 23.7 & & \\
\hline $6-<9$ & 29 & 23.4 & 5 & 6.6 & & \\
\hline$\geq 9$ & 14 & 11.3 & 16 & 21.1 & & \\
\hline \multicolumn{7}{|l|}{ Number of marriage } \\
\hline One & 120 & 96.8 & 67 & 88.2 & \multirow{2}{*}{5.7} & \multirow{2}{*}{$0.016^{*}$} \\
\hline Two & 4 & 3.2 & 9 & 11.8 & & \\
\hline \multicolumn{7}{|l|}{ Number of child } \\
\hline None & 94 & 75.8 & 76 & 100 & \multirow{2}{*}{22.9} & \multirow{2}{*}{$0.000 *$} \\
\hline One & 30 & 24.2 & 0 & 0.0 & & \\
\hline
\end{tabular}




\begin{tabular}{|c|c|c|c|c|c|c|}
\hline \multirow{2}{*}{ Characteristics } & \multicolumn{2}{|c|}{ Poor $(n=124)$} & \multicolumn{2}{|c|}{ Fair $(n=76)$} & \multirow[t]{2}{*}{$\mathbf{X}^{2}$} & \multirow[t]{2}{*}{ P. value } \\
\hline & No. & $\%$ & No. & $\%$ & & \\
\hline \multicolumn{7}{|l|}{ Residence } \\
\hline Rural & 107 & 86.3 & 58 & 76.3 & \multirow{2}{*}{3.2} & \multirow{2}{*}{$0.072^{\mathrm{ns}}$} \\
\hline Urban & 17 & 13.7 & 18 & 23.7 & & \\
\hline
\end{tabular}

${ }^{n s}$ No statistically significant difference $(p>0.05) * *$ Statistically significant difference $(p<0.05)$

Table (5): Relation between personal characteristics of infertile males attending Main Assiut University Hospital and their total score of attitude about male infertility, 2015.

\begin{tabular}{|c|c|c|c|c|c|c|}
\hline \multirow{3}{*}{ Item } & \multicolumn{4}{|c|}{ Attitude } & \multirow{3}{*}{$\mathbf{X}^{2}$} & \multirow{3}{*}{ P. value } \\
\hline & \multicolumn{2}{|c|}{ Negative $(n=131)$} & \multicolumn{2}{|c|}{ Positive (69) } & & \\
\hline & No. & $\%$ & No. & $\%$ & & \\
\hline \multicolumn{7}{|l|}{ Age } \\
\hline$<30$ & 43 & 32.8 & 23 & 33.3 & \multirow[t]{3}{*}{16.8} & \multirow[t]{3}{*}{$0.000 * *$} \\
\hline $30-<45$ & 62 & 47.3 & 46 & 66.7 & & \\
\hline$\geq 45$ & 26 & 19.8 & 0 & 0.0 & & \\
\hline \multicolumn{7}{|l|}{ Level of education } \\
\hline Illiterate & 34 & 26.0 & 4 & 5.8 & \multirow[t]{5}{*}{87.2} & \multirow[t]{5}{*}{$0.000 * *$} \\
\hline Read \& write & 4 & 3.1 & 6 & 8.6 & & \\
\hline Primary \& Preparatory & 29 & 22.1 & 6 & 8.6 & & \\
\hline Secondary & 60 & 45.8 & 28 & 40.6 & & \\
\hline University \& High & 4 & 3.0 & 25 & 36.3 & & \\
\hline \multicolumn{7}{|l|}{ Occupation } \\
\hline Government employ & 40 & 30.5 & 27 & 39.1 & \multirow[t]{3}{*}{29.6} & \multirow[t]{3}{*}{$0.000 * *$} \\
\hline Private work employ & 33 & 25.2 & 13 & 18.8 & & \\
\hline Free work & 58 & 44.3 & 29 & 42.0 & & \\
\hline \multicolumn{7}{|l|}{ Duration of married } \\
\hline$<3$ & 77 & 58.8 & 17 & 24.6 & \multirow[t]{4}{*}{86.2} & \multirow[t]{4}{*}{$0.000^{* *}$} \\
\hline $3-<6$ & 26 & 19.8 & 16 & 23.2 & & \\
\hline $6-<9$ & 0 & 0.0 & 34 & 49.3 & & \\
\hline$>9$ & 28 & 21.4 & 2 & 2.9 & & \\
\hline \multicolumn{7}{|l|}{ Number of marriage } \\
\hline One & 118 & 90.1 & 69 & 100.0 & \multirow[t]{2}{*}{7.3} & \multirow[t]{2}{*}{$0.007 * *$} \\
\hline Two & 13 & 9.9 & 0 & 0.0 & & \\
\hline \multicolumn{7}{|l|}{ No of childrens } \\
\hline None & 129 & 98.5 & 40 & 58.0 & \multirow[t]{2}{*}{60.6} & \multirow[t]{2}{*}{$0.000 * *$} \\
\hline One & 2 & 1.6 & 29 & 42.0 & & \\
\hline \multicolumn{7}{|l|}{ Residence } \\
\hline Rural & 99 & 75.6 & 66 & 95.7 & \multirow[t]{2}{*}{12.6} & \multirow[t]{2}{*}{$0.000 * *$} \\
\hline Urban & 32 & 24.4 & 3 & 4.3 & & \\
\hline
\end{tabular}

** statistically significant difference $(p<0.01)$

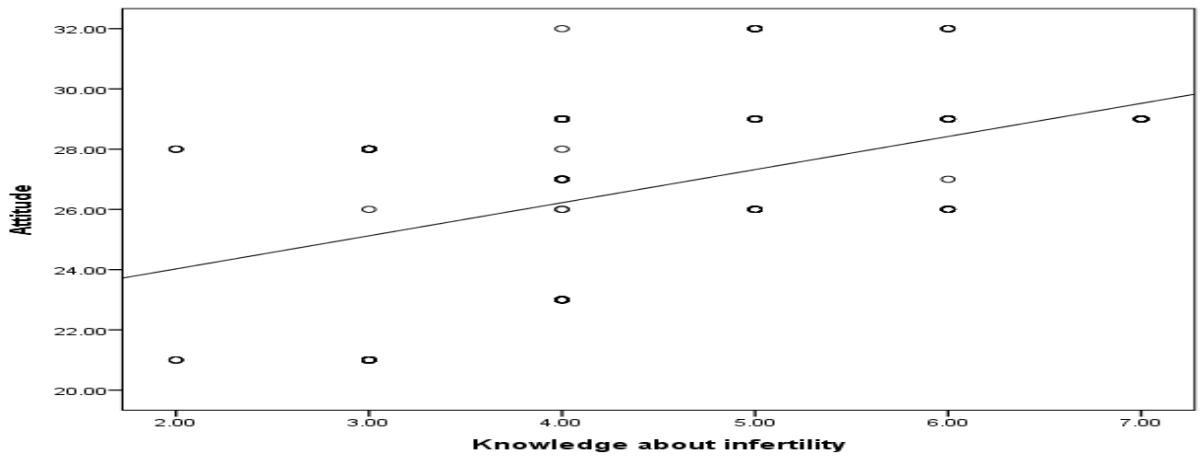

Fig (2): Correlation between total score of knowledge and total score of attitude towards male infertility among infertile males attending Main Assiut University Hospital, 2015. 
Table (1): Showed that slightly more than half (54\%) of infertile males aged $30-<45$ years. About two fifth $(39 \%)$ of the study infertile males had secondary school education, and $19 \%$ of them were illiterate. Also, this table show that more than two-fifths $(45 \%)$ of them had free work. The majority of them $(82.5 \%)$ lived in rural areas. Regarding to duration of marriage, this table reveals that $47 \%$ of them had $<3$ years duration of marriage. Also, majority of them $(84.5 \%)$ had no children,

Figure (1): Shows the total knowledge score of the infertile males about male infertility, it was observed that $62 \%$ of infertile males had poor knowledge, while more than one-third $38 \%$ of them had fair knowledge regarding male infertility.

Table (2): Shows the total attitude score of the infertile males about male infertility, it was observed that about two-thirds $65.5 \%$ of infertile males had negative attitude, $34.5 \%$ had positive attitude regarding male infertility.

Table (3): shows source of knowledge among of infertile males regarding male infertility it was observed that $(60 \%)$ of infertile males mentioned that physicians are main source of information about male infertility.

Table (4): Shows that there were statistically significant differences found between infertile male's age, level of education, occupation, duration of marriage, number of marriage, No of children and residence and their total score of knowledge about male infertility.

Table (5): Show it was cleared that there was statistically significant differences were found between infertile males' age, level of education, occupation, duration of marriage, number of marriage, number of children and residence and their total score of attitude about male infertility.

Figures (2): Illustrates that there was positive weak correlation $(r=0.058)$ between total knowledge of infertile males and their attitude. With no statistically significant correlation p.value $=0.412$.

\section{Discussion}

Infertility, defined as not being able to conceive after one year of unprotected sexual intercourse, is a global public health problem that affects more than $10 \%$ of the world's population (Rouchou \& Forde, 2015).

The findings of the present study showed that as regards to a personal characteristic of the infertile males of the present study the mean age of infertile males was $(34.9 \pm 8.9)$.These findings agree with the findings of Abdualfotouh et al., (2013) who describe knowledge, attitude, and practices of infertility among Saudi couple and reported the same age which ranges 25-40 years with the mean age of couples were $(35.05 \pm 10.05)$.

As regard to the place of residence, the majority of infertile males were from rural areas. This might explain as the rural members used pesticides during their work, also, then have low knowledge about treatment male infertility and the culture of the male infertility is a stigma. Our finding is in line with Mazeed et al., (2014) who carried out study about the infertile couple's knowledge and attitude about assisted reproductive technology. and found that infertile males were higher in rural than urban.

Regarding education level, the present study showed that about more than half of infertile males has secondary education. This is consistent with Gerhard et al., (2014) who describe the knowledge and attitudes towards infertility and its treatment. and who found that the majority $(81 \%)$ of studied sample finished secondary education.

As regard to number of marriage of infertile males, the findings of the present study presented that the majority of infertile males were in the first marriage, these findings are consistent with Mazeed et al., (2014) who carried out study about the infertile couple's knowledge and attitude about assisted reproductive technology, reported that the majority of couples were in the first marriage.

Knowledge about Infertility is inadequate in many parts of the world. A global survey of almost 17,500 women (mostly of childbearing age) from ten countries revealed that the knowledge regarding fertility and the biology of reproduction was poor Ali et al., (2011). This findings is in agreement with the findings of present study in which the level of knowledge was generally poor, as indicated by the low mean percentage score for knowledge among infertile males also supported by Diana,(2012) who describe male involvement in the management of infertile couples at Kenyatta National Hospital, who found that Male participants knowledge of infertility, causes of infertility and treatment options was generally poor.

Regarding sources of information about male infertility in the present study, it was observed that more than half of studied sample mentioned that physicians are the main source of information about male infertility because infertile man holds modesty and shame therefore to idea with information about infertility or infertility discuss the subject with relatives or friends to take them information so it takes the information from the physician also decrease health program about male infertility in mass media. this finding is supported by Bennett, et al, (2012) who describe reproductive knowledge and patient education needs among Indonesian women infertility patients attending three fertility clinics, 
who found that the most popular sources of information about infertility were obstetrician/gynecologist (OB-GYN) visit.

Regarding the relation between infertile male's total score knowledge about male infertility and personal characteristic, in the present study explored that the majority of the infertile male had poor knowledge, with a high statistically significant association found between level of knowledge and a personal characteristic such as age, education, occupation and number of children. This result agrees with Sohrabvand \& Jafarabadi, (2005), who conducted his study to assess knowledge and attitudes of infertile couples about assisted reproductive technology and who found in the session of attitude evaluation, there was an overall negative attitude about infertility and view to genetic material donation.

Also, in the present study, there was a statistically significant association found between level of attitude and a personal characteristic such as age, education, occupation and number of children. This result agrees with Gerhard et al., (2014) who conducted his study to assess awareness of and attitudes towards infertility and its treatment.in this study there was a statistically significant association found between level of attitude and a personal characteristic.

\section{Conclusion}

Based on the present study findings, it concluded that,the sample study of the infertile male had poor knowledge about male infertility and had negative attitude toward male infertility.

\section{Recommendations}

Based on the results of this study it was recommended that:-

- Health education for males about infertility.

- Provide public awareness about infertility through mass media.

- improve public awareness about the importance of premarital examination.

- Presence of a pamphlet containing information about male infertility in dermatology and anderology clinics.

\section{References}

1. Abolfotouh M., Alabdrabalnabi A., Albacker R., Al-Jughaiman, U., \& Hassan S., (2013): Knowledge, attitude, and practices of infertility among Saudi couples. International Journal of General Medicine, 23(6)563-73. http.//doi.org/10.2147/IJGM.S46884

2. Ali S., Sophie R., Imam A., \& Hasnain S., (2011): Knowledge perceptions and myths regarding infertility among selected adult population in Pakistan. a cross-sectional study. BMC Public Health 11(1) 760.

3. Bennett L., Wiweko, B., Hinting A., Adnyana I., \& Pangestu M., (2012): Indonesian infertility patients' health seeking behaviour and patterns of access to biomedical infertility care. an interviewer-administered survey conducted in three clinics. Reproductive Health, 9(1), 24.

4. El-shafy A., Ibrahim K., Ahmed S., \&Mohammed N., (2013): Mother's Knowledge and Attitude Regarding Acute Diarrhea Disease at Assiut Children's Hospital, AJN. 28(9), 15-25.

5. Fisher J., \& Hammarberg K., (2012): Psychological and social aspects of infertility in men. an overview of the evidence and implications for psychologically informed clinical care and future research Asian Journal of Andrology 14(1), 121-129.

6. Gerhard S., Ritenour W., Goodman M., Vashi D., \& Hsiao, W., (2014): Awareness of and attitudes towards infertility and its treatment. a cross-sectional survey of men in a United States primary care population Asian J Androl 16(6), 858-863.

7. Grail A., Slauson-Blevins K., \& McQuillan J., (2010): The experience of infertility. a review of recent literature Sociology of Health \& Illness 32(1), 140-62.

8. Jimoh A., (2013): The Management of Infertility, 46(1). doi:10.4314/nmp.v46i1.28717.

9. Jungwirth A., Diemer T., Dohle G., Giwercman A., Kopa Z., Krausz C., \& Tournaye H., (2012): Guidelines for the investigation and treatment of male infertility, the European Association of Urology 61(1):15963. Website - http://www.uroweb.org.

10. Lee H.,\& Park S., (2012): Causes and classification of male infertility in Korea. Clinical and Experimental Reproductive Medicine, 39(4), 172-5. http://doi.org/10.5653/cerm.2012.39.4.172

11. Mazeed S., Mohammed E., Alam H., \&Ali A., (2014): Assessment of Knowledge and Attitude of Infertile Couples toward assisted Reproductive Technologies at Assiut Women Hospital, AJN.34 (6). 50-65.

12. Mishra R., Verma H., Singh N., Singh S., \& Stress P., (2012): Male infertility . Lifestyle and infertility, Journal of Scientific Research.; 56. (93). 101- 6.

13. Orisakwe E. (2014). Male infertility in Nigeria: A neglected reproductive health issue requiring attention. Journal of Basic and Clinical Reproductive Sciences, 37(2), 5-6. 
14. Osama D., (2012): Male Involvement in the Management of Infertile Couples At Kenyatta National Hospital. a Cross-Sectional Descriptive Study of Master of Medicine in Obstetrics and Gynecology ,1-80.

15. Practice Committee of the American Society for Reproductive Medicine (2013): Definitions of infertility and recurrent pregnancy loss. Reproductive Health, 13(2),34-39.

16. Rouchou, B., \& Forde, M., (2015): Infertility Knowledge, Attitudes, and Beliefs of College Students in Grenada, 3(3), 353-360. http://doi.org/10.11648/j.sjph.20150303.18

17. Sallam H., (2013): Infertility in Egypt scince myth and religien, http.//www.iaac.ca/fr/infertility-in-egypt-sciencemyth-and-religion-3

18. Sathiyanarayanan S., Sundar S., \& Madhankumar K., (2014): A study on significant biochemical changes in the serum of infertile women. International Journal of Current Research and Academic Review, 2(2), pp. 96115.

19. Schmidt L., Holstein B., ChristensenU, \&Boivin J., (2014): Does infertility cause marital benefit? An epidemiological study of 2250 women and men in fertility treatment.Patient Edu Couns; 59(3), 244-51.

20. Smith F., Walsh J., Shindel W., Turek P., \& Katz P., (2009): Sexual marital and social impact of a man's perceived infertility diagnosis J Sex Med 6(9), 2505-2515.

21. Sohrabvand F., \& Jafarabadi M., (2005): Knowledge and attitudes of infertile couples about assisted reproductive technology Iranian Journal of Reproductive Medicine 3(2), 90-94.

22. World Health Organization., (2013): Gender and genetics. Assisted reproductive technologies (ARTs) Geneva Switzerland. World Health Organization. http://www.who.int/genomics/gender/en/index6. html. 